\title{
El folclor argentino: el caso de Zamba del carnaval de Leguizamón y Aznar
}

\section{Argentine folklore review: the case of "Zamba del carnaval" of Cuchi Leguizamon and Pedro Aznar.}

\author{
Cristopher Montero Corrales \\ Universidad Técnica Nacional, Costa Rica \\ cmontero@utn.ac.cr
}

\begin{abstract}
Resumen
Este artículo expone una breve reseña sobre la industria del folclore musical en Argentina para evidenciar sus principales pujas para la comercialización del género. Luego, se analiza la canción "Zamba del carnaval” en dos épocas distintas y su respectiva reescritura, como una muestra de la incorporación de recursos contemporáneos al folclor suramericano.

Palabras claves: folclor argentino, comercialización, reescritura, poesía

Abstract

This article features a brief review regarding the Argentinian folk music industry, which mainly deals with its main efforts to promote the genre. It also studies the song "Zamba del carnaval" as seen as the result from two different periods in time in which it was rewritten; it also displays how contemporary resources have been added to South American folk.
\end{abstract}

Keywords: Argentinian folk, promotion, rewriting, poetry 
$\mathbf{L}$ os avances técnicos que se produjeron a raíz del iluminismo y de la revolución industrial permearon todas las condiciones de vida, incluyendo la música. Esta relación entre técnica y música no es particular del siglo XX. En un sentido amplio de la técnica, toda música sería constituida por instrumentos manofactuales desde la percusión hasta el ordenador. Este entendimiento del ordenador como instrumento musical se propicia específicamente en la música concreta en los años cincuenta. Aunque, valga decir, hay sectores conservadores que todavía hoy no lo consideran así. Es un recorte de lo técnico que excluye a unos e incorpora a otros.

La revolución tecnológica del siglo XX no solo produjo centros de poder de "conocimiento" europeo, tuvo manifestaciones en las periferias y sus respectivos centros, como por ejemplo Argentina-Buenos Aires. Las fronteras están ahí como una forma de vínculo: "Así el límite es una función de la relación, un gestionar la diferencia” (Butler, 2010, pág.72).

En los años 20, surge en Argentina un movimiento que se ha llamado "industria del folclore musical". Es referido a la comercialización y difusión de esta música originalmente de la ruralidad suramericana. Este movimiento se lleva acabo en Buenos Aires, en un contexto donde la llegada de inmigrantes europeos propiciaba el establecimiento de un tipo de identidad nacional. Esto lo afirma Frith (1987) respecto a la música popular en su generalidad: "La primera razón por la cual disfrutamos de la música popular se debe a su uso como respuesta a cuestiones de identidad: usamos las canciones del pop para crearnos a nosotros mismos una especie de autodefinición particular, para darnos un lugar en el seno de la sociedad" (pág.7).

Para algún sector purista del folclore, esta comercialización - que se dio mayormente por radiodifusión- desvirtúa las características "verdaderas" del folclore, ya que lo aleja de su ámbito rural. También, lo moderniza de distintas formas, y esto le quita su contacto con la naturaleza. Valga aclarar que hay una puja naturaleza/cultura, típica de la época, que busca proteger la música popular de los males de las sociedades modernas, es decir: la espectacularización que luego denunciraría Debord (1987):

El espectáculo, comprendido en su totalidad, es a la vez el resultado y el proyecto del modo de producción existente. No es un suplemento al mundo real, su decoración añadida. Es el corazón del irrealismo de la sociedad real. Bajo todas sus formas particulares, información o propaganda, publicidad o consumo directo de diversiones, el espectáculo constituye el modelo presente de la vida socialmente dominante. (pág. 9)

Esta puja permite entender la naturaleza como algo noble o puro sin enfermedades, al contrario de la cultura: "La naturaleza es un sistema sin azar ni juicios. En ella no hay dolor -ni vida ni muerte-, solo plenitud. La cultura -su otra cara- es tan solo un conjunto de valores para atormentarnos." (Sólorzano-Alfaro, 2017, pág.23)

Es así como estos movimientos que se oponían a incorporar la música popular al aparato moderno, que llamaremos "tradicionalistas", se muestran escépticos a las características de la industria cultural, 
como lo son "el afán de lucro, el aprovechamiento de la tecnología de los medios masivos de comunicación, el aparato publicitario... y que naturalmente, deben ser tenidos en cuenta en cualquier esfuerzo por dar cuenta de las modalidades de las prácticas culturales en ella articuladas" (Kaliman, 2016 , pág.4). También es importante mencionar que se desarrolló una "proyección folclórica" como una forma de resolver esta incorporación a las grandes urbes y sus contextos, con la salvedad de que el folclore mantuviera lo esencial.

Surgen, con esta difusión del folclore musical, diversas perspectivas de índole teórico-estética que sirven como mecanismos de identificación (integración/exclusión) de ciertos grupos en un binomio: popular/ ilustrado. Sin duda, resuena en las dicotomías "alta cultura/cultura popular" y en la música, específicamente, ha tenido el rostro de "música seria/música popular":

En la base de cualquier distinción crítica entre la música «seria» y la «popular» subyace una presunción sobre el origen del valor musical. La música seria es importante porque trasciende las fuerzas sociales; la música popular carece de valor estético porque está condicionada por ellas (porque es «útil»»o «utilitaria»). (Frith,1987, pág.1)

Esta distincion (popular/ ilustrado) se hace con una intención de referencialidad ya que no se pueden dividir dos mundos de folclore tan tajantemente. También, existen muchos matices que dinamizan la relación entre estas dos esferas. Lo que sí es cierto es que son posturas que, con sus matices, están en puja y en debate discursivo, proponiendo lenguajes "propios" que buscan legitimar una u otra postura y su perdurabilidad; como afirman Berger y Luckman: "al mismo tiempo que el aparato conversacional mantiene continuamente la realidad, también la modifica de continuo" (1986, pág.14).

Para la década del 50, se publica "el nuevo cancionero" que es un manifiesto donde un grupo de folcloristas resuelve, de alguna forma, esta puja. Se declinan por una mirada que renueve el género y que no desaproveche ningún aporte que pueda brindarle la modernidad. Aprovechar la diversidad de las manifestaciones artísticas para beneficio del folclore, teniendo clara la importancia de un arraigo en el ser-tradicionalista, “...intentará asimilar todas las formas modernas de expresión que ponderen y amplíen la música popular... Aspira a renovar, en forma y contenido, nuestra música, para adecuarla al ser y el sentir del país de hoy" (Kaliman, 2016, pág.14).

Este manifiesto que Kaliman (2016) ubica en el esquema de la "distinción" entendida como "la expresión auténtica pero necesariamente sencilla y conservadora del pueblo; por otra, la versión superadora de esas formas de expresión a cargo del artista creador, con la capacidad de administrar las formas más elevadas de belleza" (pág14.) sería de suma importancia, ya que influencia la práctica de otros artistas posteriores como Gustavo "euchi" Leguizamón $\mathrm{y}$, posteriormente, reescrituras textuales $\mathrm{y}$ musicales. La reescritura, que permite la incorporación de otros formatos, instrumentos o contextos y le agrega complejidad al ambiente folclórico, es entendida como:

toda operación que consiste en transformar un texto A para llegar a un texto B, 
cualquiera que sea la distancia en cuanto a la expresión, el contenido y la función, así como todas las prácticas de «seconde main»: copia, cita, alusión, plagio, parodia, pastiche, imitación, transposición, traducción, resumen, comentario, explicación, corrección. (Cayuela, 2000, pág.37)

Por otro lado, no solo tienen conexiones culturales e históricas, sino inventivas y personales del autor, donde plasma su contemporaneidad, su forma de escindir el tiempo, como por ejemplo la reescritura de Pedro Aznar de "Zamba del carnaval" de Leguizamón que analizaremos a continuación:

"Zamba del Carnaval"

Letra y música: Gustavo Leguizamón

Vengo desde el olvido,

toro serrano,

por ver si mato penas

carnavaleando.

Me anda faltando plata,

chicha, coraje

y un empujón del diablo

pa' enamorarte.

Carnavales carperos,

la copla y la albahaca

llorando en el vino.

Los caballos atados

vuelven a la luna

galope tendido.

Bailaremos la zamba

los dos solitos

para trampearte el alma

con mi gualicho.

Tu pañuelito blanco

busca consuelo,

mi corazón lo sigue

de vuelo en vuelo.

Carnavales carperos,

la copla, la albahaca

llorando en el vino.

Los caballos atados

vuelven a la luna galope tendido.

"Zamba del Carnaval"

Letra y música: Pedro Aznar

Vengo desde el olvido

toro serrano

$\mathrm{Pa}^{\prime}$ ver si mato penas

carnavaleando

Me anda faltando plata

chicha, coraje

y un empujón del diablo

pa' enamorarte

Carnavales carperos

la chicha y la albahaca llorando en el vino

Los caballos atados vuelven a la luna al galope tendido

Y un empujón del diablo me anda faltando

Ven, bailemos la zamba

los dos solitos

quiero trampearte el alma

con mi gualicho

Tu pañuelito al aire

busca consuelo

Mi corazón lo sigue

de vuelo en vuelo

Carnavales carperos

la chicha y la albahaca llorando en el vino

Los caballos atados vuelven a la luna al galope tendido

Y un empujón del diablo me anda faltando

\section{Análisis textual}

Los dos poemas tienen 6 estrofas. Ambos se separan del octosílabo tradicional. A diferencia del poema de Leguizamón - que son versos menores- el poema de Aznar se constituye con el uso de algunos versos mayores en el estribillo. Este cambio en el metro del estribillo se hace para agregar un verso referido a la incertidumbre 
desdichada del amor: "Y un empujón del diablo me anda faltando". Este verso hace énfasis en esta incertidumbre que conforma el amor; según Bauman (2003) intentar arradicar esa duda implicaría el final del amor: "Mientras está vivo, el amor está siempre al borde de la derrota" (pág.61).

En la primera estrofa no hay modificación en la letra sino hasta el tercer verso donde "por ver si mato penas" se vuelve " $\mathrm{Pa}$ ' ver si mato penas". La última versión tiene un carácter coloquial de la norma mientras la primera versión denota el motivo sin mucha explicación. La versión de Aznar es un guiño a lo coloquial desde la norma, explicando si se quiere, su intención.

En la segunda estrofa no hay reescritura alguna en la letra. La versión de Aznar mantiene intacta la letra, presumiblemente, debido a que es lo suficientemente comprensible dentro del contexto actual. También, mantiene la preocupación del hablante por conseguir el amor de la mujer y su carácter de incierto y de desdicha. A diferencia de algunas versiones como la de Abel Pintos que cambia el último verso por " $\mathrm{pa}^{\mathrm{\prime}}$ enamorarme", cambiando y confundiendo así la preocupación del hablante por conseguir el amor de su amada.

Luego, un estribillo donde Aznar hace uso de algunos versos mayores. Estos le permiten que sea más explícita la imagen y remarcar -como se mencionó anteriormente en el último verso- el carácter azaroso del amor. Le explica al lector la imagen con esa contracción gramatical "al". Este cambio podría referirse a un lector menos preparado para la densidad de la imagen poética en los contextos actuales.

La cuarta estrofa inicia con una afirmación en el poema de Leguizamón: "Bailaremos la zamba"; en la otra versión es una invitación: "Ven, bailemos la zamba". La última implica tener en cuenta al otro, a la mujer. La versión de Aznar la actualiza, luego de las reivindicaciones de género que han existido en la actualidad y la pone en contacto con el ser-estar que se pretende actualmente, lejos del otro ser-tradicional.

La última estrofa antes del estribillo le permite movimiento al pañuelo que se presume que es blanco. En la versión de Leguizamón se trata de un pañuelo blanco sin hacer movimiento y es la única estrofa que usa la rima consonante en el segundo y cuarto versos.

Aparece el estribillo que le da importancia al azar y a la incertidumbre que es el amor con: "Y un empujón del diablo me anda faltando", en consonancia con épocas de postulados posmodernos que cada vez desconfían más del control y privilegian la aceptación de la incertidumbre.

La reescritura de Aznar nos refiere a la escritura como intertextual. No se puede entender aislada del contexto históricocultural, y la reescritura como una forma de poner en contacto contextual textos que, debido a las dinámicas culturales, han perdido fuerza en el presente. En este caso podrían ser las reivindicaciones de género o un público que necesita versos mayores y claros, no acostumbrados a los versos menores de la zamba. Por otro lado, la 
obra de Aznar no se caracteriza por ser exclusivamente folclórica; le exige poner en contacto a un público contemporáneo con textos de la década del 60 y reescribirlos en la actualidad de sus registros.

La versión de Leguizamón se acompaña de una guitarra únicamente, a diferencia de la de Aznar, donde el cantante se acompaña de un bajo. Esta característica de la puesta en escena aznarniana es una novedad en el folclore que implica la inserción de un instrumento que tradicionalmente no fue utilizado en estas propuestas. Otras incorporaciones novedosas son: la batería con escobilla, redoblante y platillo en estrecha relación con la percusión del bombo $\mathrm{y}$, sin duda, la armónica.

Agregado a esto, estiliza contemporáneamente el tema con una introducción con voz siguiendo la melodía de la zamba, haciendo un guiño al scat singing del jazz. Y, además, agregando varios interludios para hacer solos, constituyendo así el tema con dos minutos más que la versión de Leguizamón.

La reescritura de Aznar de "Zamba del carnaval" la pone en contacto con el contexto cultural contemporáneo y no cambia la melodía ni su tiempo, lo cual la hace percibirse como que viene de otro tiempo y espacio pero comprendida en la actualidad.

Este tipo de reescrituras abre el panorama a la complejidad del fenómeno del folclore musical y lo inserta en interpretaciones que se mezclan con otros géneros que, al parecer, le pueden ser muy extraños y los ponen en contacto con su época, como lo pueden hacer el jazz pero también el raggaeton y son híbridos que merecen su reflexión en el marco de los movimientos del folclore.

La reescritura de Aznar lleva al máximo las incorporaciones de recursos de toda índole. Pone en contacto este poema con públicos masivos en contextos multitudinarios y ya no solo el festival o las peñas. Este tipo de género musical, que constituye un gesto importante dentro del sentimiento nacional y de la memoria argentina, propicia reelaboraciones que permitan conectar con los nuevos públicos y contextos y evidenciar ese centauro (gaucho) de quien nos hablaba Sarmiento por medio de la poesía en el folclor.

\section{Referencias}

Bauman, Z. (2003). Amor líquido. Sobre la fragilidad de los vínculos humanos. Recuperado el 01 de noviembre de 2017 de http://assets. espapdf.com/b/Zygmunt\%20Bauman/Amor\%20liquido\%20(3071)/ Amor\%20liquido\%20-\%20Zygmunt\%20Bauman.pdf

Berger, P. y Luckman, T. (1986). La construcción social de la realidad. Buenos aires: Amorrortu Editores.

Butler, J. (2010). Marcos de guerra. Las vidas lloradas. Buenos Aires: Paidós.

Cayuela, A. (2000). De reescritores y reescrituras. Recuperado el 18 de abril del 2017 de http://cvc. cervantes.es/literatura/criticon/ PDF/079/079_039.pdf 
Debord, Guy. (1994). La sociedad del espectáculo. Recuperado el 20 de abirl del 2017 de http://criticasocial. cl/pdflibro/sociedadespec.pdf

Frith, S. (1987). Hacia una estética de la música popular en The politics of composition, performance and reception Traducción de Silvia Martínez. Cambridge: Cambridge University Press.

Kaliman, R. (2016). Dos actitudes ilustradas hacia la música popular. Para una historia social de la industria del folklore musical argentino. Revista Argentina de Musicología, vol. 17 , p. $37-56$.

(2003). Un gualicho mejor. Las letras de amor de la zamba argentina. Investigaciones folclóricas, p. 167-178. Buenos Aires.

Solórzano Alfaro, G. (2017). Nadie que esté feliz escribe. Santiago: Nadar Ediciones. 